9. Liu L, Li X, Ma J, et al. The molecular architecture for RNA-guided RNA cleavage by Cas13a. Cell. 2017;170:714-726.e10. DOI: 10.1016/ j.cell.2017.06.050.

10. O'Connell MR, Oakes BL, Sternberg SH, et al. Programmable RNA recognition and cleavage by CRISPR/Cas9. Nature. 2014;516:263-266. DOI: 10.1038/nature13769.

11. Strutt SC, Torrez RM, Kaya E, et al. RNA-dependent RNA targeting by CRISPR-Cas9. Elife. 2018;7. DOI: 10.7554/eLife.32724.

12. Gootenberg JS, Abudayyeh OO, Kellner MJ, et al. Multiplexed and portable nucleic acid detection platform with Cas13, Cas12a, and Csm6. Science. 2018 Feb 15 [Epub ahead of print]. DOI: 10.1126/science.aaq0179.
13. Abudayyeh OO, Gootenberg JS, Essletzbichler $P$, et al. RNA targeting with CRISPR-Cas13. Nature. 2017;550:280-284. DOI: 10.1038/nature24049.

14. Cox DBT, Gootenberg JS, Abudayyeh OO, et al. RNA editing with CRISPRCas13. Science. 2017;358:1019-1027. DOI: 10.1126/science.aaq0180.

15. Smargon AA, Cox DBT, Pyzocha NK, et al. Cas13b is a Type VI-B CRISPRassociated RNA-guided RNase differentially regulated by accessory proteins Csx27 and Csx28. Mol Cell. 2017;65:618-630 e617. DOI: 10.1016/j.molcel.2016.12.023.

16. Metkar M, Ozadam H, Lajoie BR, et al. Higher-order organization principles of pre-translational mRNPs. bioRxiv. 2018 Mar 8 [Preprint]. DOI: https://doi.org/10.1101/278747.

\title{
ARRIGE Arrives: Toward the Responsible Use of Genome Editing
}

\author{
Lluis Montoliu, Jennifer Merchant, 2,3 François Hirsch, ${ }^{3}$ Marion Abecassis, ${ }^{3}$ Pierre Jouannet, ${ }_{1}^{3,4}$
} Bernard Baertschi, ${ }^{3,5}$ Cyril Sarrauste de Menthière, ${ }^{6}$ and Hervé Chneiweiss ${ }^{3,7}$

\section{In March 2018, Approximately 160 Participants from 35 Countries Gathered in Paris to Launch the ARRIGE (Association for Responsible Research and Innovation in Genome Editing) Initiative}

Genome editing is a transformative technology that allows precise and sophisticated genetic alterations in any genome thanks to a variety of molecular editors. The CRISPR*-Cas9 genome-editing technology, derived from prokaryotic adaptive immune systems, has transformed targeted editing into a practical reality, widely available and affordable. ${ }^{1}$ Numerous applications have already been explored in model systems, animals, and plants for biological and biotechnological purposes, improving the production and nutritional value of food, and/or improving adaption to an environment. However, biomedical applications - the great hope for treating and potentially curing many genetic diseases-have yet to be effectively deployed, requiring the careful evaluation of safety and efficacy constraints before entering the clinic.

*Clustered Regularly Interspaced Short Palindromic Repeats.

${ }^{1}$ National Centre for Biotechnology (CNB-CSIC), CSIC Ethics Committee and Biomedical Research Networking Centre Consortium on Rare Diseases (CIBERER-ISCIII), Madrid, Spain; ${ }^{2}$ University Panthéon-Assas, Paris, France; ${ }^{3}$ French National Institute for Health and Medical Research (INSERM) Ethics Committee, France; ${ }^{4}$ University Paris Descartes, Paris, France; ${ }^{5}$ University of Geneva, Geneva, Switzerland; ${ }^{6}$ Institute of Human Genetics (IGH), National Center for Scientific Research (CNRS), University of Montpellier, Montpellier, France; ${ }^{7}$ CNRS UMR8246, INSERM U1130 and University Pierre and Marie Curie UMCR18, Neuroscience Paris Seine-IBPS, Team Glial Plasticity, Paris, France.

Address correspondence to: Lluis Montoliu, National Centre for Biotechnology (CNB-CSIC), CSIC Ethics Committee and Biomedical Research Networking Centre Consortium on Rare Diseases (CIBERER-ISCIII), Darwin 3, Madrid 28049, Spain, E-mail: montoliu@cnb.csic.es

(C) Lluis Montoliu et al. 2018; Published by Mary Ann Liebert, Inc. This Open Access article is distributed under the terms of the Creative Commons License (http:// creativecommons.org/licenses/by/4.0), which permits unrestricted use, distribution, and reproduction in any medium, provided the original work is properly cited. 


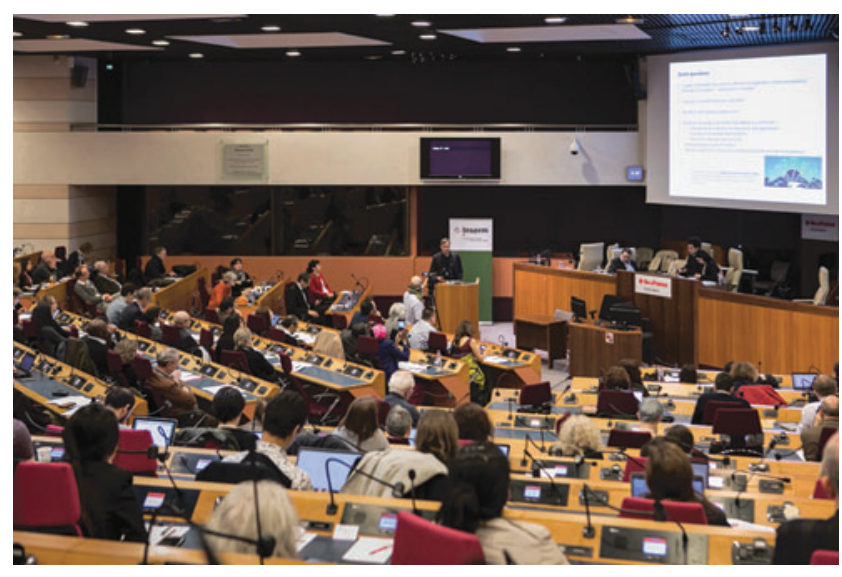

FIG. 1. ARRIGE kick-off meeting at the Region île-deFrance Parliament in Paris on March 23, 2018. (Photograph courtesy of INSERM.)

about what, where, for which purposes, who, and how many animals are to be used in the proposed research. Raised awareness is a key first step to allow public stakeholders to debate and judge the uncertainties and transformative potential of genome-editing technologies.

\section{The French Connection}

In 2015 a group of researchers and ethicists from France and neighboring countries, initiated by the National Institute for Health and Medical Research (INSERM) Ethics Committee, began organizing a series of meetings in Europe, India, Africa, and South America, addressing the diverse ethical issues associated with the responsible use of genome editing as applied to humans, animals, plants, and the environment. The initial position of this group, projected from Europe, was first reported in early $2017 .^{3}$ The proposal was expanded upon in a longer paper published last summer that proposed the creation of a European Steering Committee to assess the potential benefits and risks of genome editing, design risk matrices and scenarios for responsible uses of this technology, and contribute to an open debate on societal aspects prior to a translation into national and international legislation. ${ }^{4}$

In November 2017, INSERM held an important meeting in Paris to examine many existing reports, position papers, and manifests on the ethical and societal aspects of genome editing and the responsible uses of these technologies (reviewed by de Lecuona et al.). ${ }^{5}$ We wanted to go beyond the publication of a simple report: we wished to become useful, operative, proactively engaging the various stakeholders mentioned above in this debate.

From that meeting, it also became clear that the scope of this initiative had to be truly international, going be- yond the usual perspectives from Europe, North America, China, Japan, and Australia and involving the oft-forgotten south by including members from Southeast Asia, Africa, and Central/South America. Those discussions crystalized in the March 23, 2018, conference at Ille-de-France regional Parliament in Paris, featuring approximately 160 participants from 35 countries. Here we decided to launch the ARRIGE initiative (Fig. 1).

The aim of this new nonprofit initiative is to promote a global governance of genome editing through a comprehensive setting for all stakeholders-academics, researchers, clinicians, public institutions, private companies, patient organizations, and other nongovernmental organizations, regulators, citizens, media, governmental agencies, and decision makers from all continents. We hope to address multiple issues raised by genome-editing technologies used in research and applications within a safe and ethical framework for individuals and society.

More specifically, the ARRIGE association aims to provide a vehicle for meetings and outreach with the following four major objectives:

(1) fostering an inclusive debate with a risk-management approach, considering human, environmental, animal, and economic issues;

(2) getting involved in the governance of genomeediting technology with governmental and intergovernmental stakeholders;

(3) creating an ethical toolbox and informal guidance for genome-editing technology users, regulators, governance, and the civil society at large, including those living in low- and middle-income countries; and

(4) developing a robust and specific reflection on the role of the lay public in this debate and the necessity for improved public engagement.

Coincidentally, the same week of our March meeting in Paris, a similar proposal was published in Nature, suggesting the creation of a global observatory and requesting a cosmopolitan conversation on the uses, applications, and consequences of genome editing technologies. ${ }^{6}$ These proposals were independent of each other. However, thanks to media outreach, ${ }^{7}$ we look forward to working collaboratively in pursuit of our common aims and interests.*

\section{References}

1. Mojica FJM, Montoliu L. On the Origin of CRISPR-Cas technology: from prokaryotes to mammals. Trends Microbiol. 2016;24:811-820. DOI: 10.1016/j.tim.2016.06.005.

*For more information, contact the ARRIGE initiative (join@arrige.org) and/or visit the ARRIGE web site, which hosts various documents, talks, and videos (http://arrige.org). 
2. Jarrett $\mathrm{W}$. The Concordat on openness and its benefits to animal research. Lab Anim (NY). 2016;45:201-202. DOI: 10.1038/laban.1026.

3. Hirsch F, Lévy Y, Chneiweiss H. CRISPR-Cas9: A European position on genome editing. Nature. 2017;541:30. DOI: 10.1038/541030c.

4. Chneiweiss $H$, Hirsch $F$, Montoliu L, et al. Fostering responsible research with genome editing technologies: a European perspective. Transgenic Res. 2017;26:709-713. DOI: 10.1007/s11248017-0028-z.
5. de Lecuona I, Casado M, Marfany G, et al. Gene Editing in humans: towards a global and inclusive debate for responsible research. Yale J Biol Med. 2017;90:673-681. eCollection 2017 Dec.

6. Jasanoff S, Hurlbut JB. A global observatory for gene editing. Nature. 2018;555:435-437. DOI: 10.1038/d41586-018-03270-w.

7. Enserink M. Interested in responsible gene editing? Join the (new) club. Science News, March 27, 2018. www.sciencemag.org/news/2018/03/interestedresponsible-gene-editing-join-new-club (last accessed April 4, 2018).

\section{It's CRISPR Clear: Off-Target Study Misses the Mark}

Shondra M. Pruett-Miller

\section{A Controversial 2017 Nature Methods Report Raising Concerns About Off-Target Genome Editing in Mice Has Been Retracted}

When you were little, did you ever hear a bump in the night and assume the worst? The noise could be a scary monster, the neighbor's cat, or just your kid sister. It's only natural to assume the worst, but assumptions are not conclusive-especially without proper controls.

In May 2017, a group led by Stanford University physician-scientist Vinit B. Mahajan published a brief report in Nature Methods that claimed that CRISPR*-Cas9 edited mice had a multitude of unexpected mutations. ${ }^{1}$ The study gained widespread attention and hurt the stock prices of several CRISPR-based biotech companies. After sequencing only two edited mice, the authors tallied the widespread genomic differences between a strain control animal (Fig. 1) maintained in a separate colony and the two edited animals and attributed these differences to offtarget effects of the CRISPR treatment. (The CRISPR treatment involved zygote injections of one single guide RNA [sgRNA] plasmid, Cas9 protein, and an oligo donor. Of note, the use of a sgRNA expressing plasmid along with Cas9 protein was unconventional because of temporal expression differences. Furthermore, impor-

*Clustered Regularly Interspaced Short Palindromic Repeats. tant details such as which sgRNA expression plasmid and Cas9 protein were injected were not included in the original publication.)

This study quickly drew criticism: within a couple of weeks, the journal issued an editorial note explaining that "the conclusions of this paper are subject to criticisms that are being considered by editors." " A month later, Nature Methods added an editorial "expression of concern" and warned that "since the background genetic variation between the control mouse and the CRISPR-treated animals is not known, an alternative proposed interpretation is that the observed changes are due to normal genetic variation."1

On March 30, 2018, the journal finally issued a formal retraction, stating that "without proper controls or more analysis of genetic background, it is not certain that the variants reported are due to CRISPR treatment." "The retraction (approved by just two the original six authors) was accompanied by the publication of five letters to the editor, including correspondence from several CRISPR biotech companies, critiquing the original paper. ${ }^{2-6} \mathrm{~A}$ Nature Methods editorial acknowledged that the originally selected referees lacked expertise in the genetic variation of inbred mouse strains. ${ }^{7}$

Center for Advanced Genome Engineering, Department of Cell and Molecular Biology, St. Jude Children's Research Hospital, Memphis, Tennessee.

Address correspondence to: Shondra M. Pruett-Miller, Center for Advanced Genome Engineering, Department of Cell and Molecular Biology, St. Jude Children's Research Hospital, 262 Danny Thomas Place, Memphis, TN 38105, E-mail: Shondra.Miller@STJUDE.ORG 